\title{
Susceptibility of Pacific Yew to Phytophthora lateralis
}

\author{
Marion S. Murray and Everett M. Hansen, Department of Botany and Plant Pathology, Oregon State University, \\ Corvallis 97331
}

\begin{abstract}
Murray, M. S., and Hansen, E. M. 1997. Susceptibility of Pacific yew to Phytophthora lateralis. Plant Dis. 81:1400-1404.

In 1991, Pacific yew was reported as a new host for Phytophthora lateralis, an aggressive root pathogen thought previously to be specific to Port Orford cedar. This study was designed to compare the pathogenicity of $P$. lateralis on the two hosts through seedling, stem, branch, and rootlet inoculations, and field survey. Mortality of inoculated plants averaged $72 \%$ for cedar and $4 \%$ for Pacific yew, and root colonization by $P$. lateralis was significantly greater in cedar seedlings than in Pacific yew seedlings. Lesion length on the cedar seedling stems was twice the lesion length on Pacific yew stems, and cedar branches had lesions four times longer than Pacific yew branches. Abundant zoospore aggregation occurred on cedar rootlets along the zone of elongation and the region of maturation. In comparison, far fewer zoospores encysted on Pacific yew rootlets, and they were concentrated on the root hairs. A field survey along $0.8-\mathrm{km}$ stretches of three infested streams in southwest Oregon and northwest California revealed a total of 1,199 dead Port Orford cedar (46\% mortality), and 86 dead Pacific yew (10\% mortality). We conclude that Pacific yew is less susceptible to $P$. lateralis than Port Orford cedar.
\end{abstract}

Pacific yew (Taxus brevifolia Nutt.) is a forest tree native to the Pacific Northwest and regions of the Rocky Mountains. It is a short tree, often shrub-like, that grows in the understory of western coniferous forests. It provides food and cover for wildlife, shades stream bottoms, and contributes to stream channel stabilization through its fibrous root system. Wood of the Pacific yew was valued by Native Americans for making tools and hunting implements, and is valued today for ornamental woodworking (11). Pacific yew gained shortlived fame after a report that taxol, a chemical extracted from its bark, had antitumor activity in humans (17). For several years this tree was heavily harvested on state and federal lands for taxol extraction. The exploitation of this species eventually led to the need for a Federal Environmental Impact Statement, completed in September of 1993. Taxol can currently be synthesized (13), reducing the economic demands on Pacific yew.

Phytophthora lateralis Tucker \& Milbrath, once thought to be host specific on Port Orford cedar (Chamaecyparis lawsoniana (A. Murr.) Parl.), was reported on

Corresponding author: E. M. Hansen

E-mail: hansene@bcc.orst.edu

This research was supported by the Siskiyou National Forest and the Forest Insect and Disease Management Group, USDA Forest Service, Portland, Oregon.

Accepted for publication 28 July 1997.

Publication no. D-1997-1023-01R

(C) 1997 The American Phytopathological Society
Pacific yew in 1991 (5). The pathogen is believed to have been introduced to the range of Port Orford cedar based on its sudden appearance, aggressive pathogenicity, and the fact that little resistance has been seen in the field. Port Orford cedar has been severely affected in its native range and in ornamental plantings on the West Coast, and the ornamental Port Orford cedar nursery industry has been nearly eliminated (19). Monetary losses range in the millions of dollars, and ecosystem function in riparian areas may be altered due to loss of the cedar overstory. The pathogenicity of $P$. lateralis on Port Orford cedar has been well documented (14-16). Little is known, however, about the infection biology of the fungus on $\mathrm{Pa}$ cific yew.

In 1991, P. lateralis was isolated from 17 of 44 dead Pacific yew trees identified during a United States Forest Service field survey (DeNitto, United States Department of Agriculture [USDA] Forest Service staff report). The overall extent of mortality of Pacific yew throughout the range of Port Orford cedar has not been determined. Our primary objective was to compare the relative susceptibility of Pacific yew and Port Orford cedar to infection by $P$. lateralis. We compared inoculation success on seedlings and rooted cuttings and on excised branches, and zoospore attraction to roots. We also measured mortality rates along three streams in the forest.

\section{MATERIALS AND METHODS}

Root inoculation. Pacific yew seedlings and rooted cuttings and Port Orford cedar seedlings were inoculated by root dip in a zoospore suspension, or by adding chlamydospores to the potting mix. Controls were uninoculated. Two isolates of $P$. lateralis were combined for the inoculations. Isolate 366 was collected by John Kliejunas, USDA Forest Service, in 1986 from a Port Orford cedar tree on the Gasquet Ranger District of Six Rivers National Forest in northern California, and recovered from liquid nitrogen storage at Oregon State University (OSU) in 1992. Isolate 91-9-9-2 was collected by Gregg DeNitto, USDA Forest Service, in 1990 from a Pacific yew tree in northwest California. Isolates were maintained on corn meal agar at $25^{\circ} \mathrm{C}$ in the dark, and subcultured biweekly.

Pacific yew seedlings were obtained from a Weyerhaeuser Company nursery (Group 1), and both seedlings and rooted cuttings were obtained from a USDA Forest Service (FS) nursery (Group 2). All Pacific yew trees used as seed or cutting sources were growing within the range of Port Orford cedar. The Group 1 seedlings were approximately 4 years old, and averaged $65 \mathrm{~cm}$ in height, $1.3 \mathrm{~cm}$ in diameter at the root collar, and $32 \mathrm{~cm}$ in total root length. The Group 2 seedlings were 2 years old, and averaged $45 \mathrm{~cm}$ in height, $0.4 \mathrm{~cm}$ in diameter at the root collar, and $21.1 \mathrm{~cm}$ in total root length. The Group 2 rooted cuttings were 2 years old, averaged $35 \mathrm{~cm}$ in height, $0.5 \mathrm{~cm}$ in diameter at the root collar, and $20.2 \mathrm{~cm}$ in total root length. Port Orford cedar seedlings were from mixed sources, and averaged 4.5 years in age, $95 \mathrm{~cm}$ in height, $1.5 \mathrm{~cm}$ in diameter at the root collar, and $26.6 \mathrm{~cm}$ in total root length. All plant material was kept in the greenhouse at temperatures near $24^{\circ} \mathrm{C}$ during the day and $15^{\circ} \mathrm{C}$ at night, without supplemental light sources.

The Group 1 and Group 2 Pacific yew materials were inoculated separately. Zoospore and chlamydospore inoculation techniques were also tested separately. There were thus four inoculation trials, each trial including inoculated and control Pacific yew and inoculated and control Port Orford cedar. A total of 50 Pacific yew seedlings, 40 rooted cuttings, and 36 Port Orford cedar seedlings were inoculated.

Zoospore suspensions for root dip inoculation were prepared by growing $P$. lateralis in pea broth amended with 20 ppm $\beta$-sitosterol (6) in 100 - by $15-\mathrm{mm}$ petri plates for 7 days in the dark at $17^{\circ} \mathrm{C}$. Mycelial colonies were then rinsed with distilled water, flooded with filter sterilized creek water, and incubated at $17^{\circ} \mathrm{C}$ in the dark for $24 \mathrm{~h}$. Zoospore emergence typi- 
cally began 17 to $20 \mathrm{~h}$ after addition of the creek water.

Seedlings and cuttings were removed from their potting soil, roots were clipped to a length of 13 to $14 \mathrm{~cm}$, and 3 seedlings of the same species were suspended in a 1liter plastic container holding $40 \mathrm{ml}$ zoospore suspension (20 $\mathrm{ml}$ from each isolate) plus $100 \mathrm{ml}$ distilled water. Final zoospore concentration was $6.6 \times 10^{3} / \mathrm{ml}$ for Group 1 and $5.4 \times 10^{3} / \mathrm{ml}$ for Group 2. The control inoculation consisted of clipping the root ends and placing the seedlings and rooted cuttings in plastic containers holding $140 \mathrm{ml}$ distilled water. After $24 \mathrm{~h}$, the seedlings and rooted cuttings were repotted and placed on the greenhouse bench where they were watered every three to four days for 15 weeks.

Chlamydospore inoculum was prepared from isolates grown in pea broth amended with $20 \mathrm{ppm} \beta$-sitosterol, as described above. Mycelial colonies were then rinsed with distilled water, macerated with a household blender for 10 to $15 \mathrm{~min}$, and filtered through a $1-\mathrm{mm}^{2}$ metal sieve, then through one-ply cheesecloth. Chlamydospore concentrations averaged $1.2 \times 10^{3}$ spores/ml for the Group 1 inoculation and $1.1 \times 10^{3}$ spores $/ \mathrm{ml}$ for the Group 2 inoculation. One $\mathrm{ml}$ of the chlamydospore inoculum was poured directly into each of three 9-cm-deep holes around the stem of the potted seedling or rooted cutting. Distilled water replaced the chlamydospore inoculum for the control seedlings and cuttings. After inoculation, each pot was flooded for $24 \mathrm{~h}$ to induce sporangia and zoospore release. Seedlings and rooted cuttings were then placed on the greenhouse bench to drain and watered every three to four days for 15 weeks.

Recovery of $P$. lateralis was attempted by baiting from all Pacific yew materials and a portion of the Port Orford cedar seedlings (8). Five root pieces from each seedling were excised from areas where necrotic and healthy phloem tissue converged. Root pieces were then placed in a container with $100 \mathrm{ml}$ distilled water amended with $25 \mathrm{ppm}$ hymexazol, on which 4 1-cm-sections of fresh Port Orford cedar foliage floated as bait. After 7 days, the foliage was plated onto corn meal agar with $10 \mathrm{ppm}$ pimaricin, $250 \mathrm{ppm}$ ampicillin, and $10 \mathrm{ppm}$ rifampicin. Plates were examined for characteristic growth of $P$. lateralis after 3 to 4 days' incubation at $25^{\circ} \mathrm{C}$ in the dark.

Branch and stem inoculations. For stem inoculations, 15 healthy Port Orford cedar and 30 healthy Group 1 Pacific yew seedlings were chosen. Additionally, branches were cut from 6 mature Pacific yew trees and 1 Port Orford cedar tree growing near Corvallis, Oregon, and 7 Pacific yew trees and 2 Port Orford cedar trees growing on the Illinois Valley Ranger District in the Siskiyou National Forest. Five 1-m-long branches were cut from each selected tree and transported promptly to the greenhouse. In the greenhouse, ends were recut and immersed in water in buckets. Seedling stems and tree branches, each with appropriate control material, were inoculated separately.

Mycelial inoculum was prepared by growing $P$. lateralis in pea broth in petri dishes for 7 days in the dark at $17^{\circ} \mathrm{C}$. Wound inoculations were performed on intact seedlings between 5 and $10 \mathrm{~cm}$ above the soil line. Branch inoculations were made at mid-stem, where the diameter was between $4 \mathrm{~mm}$ and $1 \mathrm{~cm}$. A $1-\mathrm{cm}$ longitudinal cut was made through the bark on each seedling or branch. A $1-\mathrm{mm}^{3} \mathrm{sec}-$ tion of actively growing mycelium was inserted into the wound and covered with petroleum jelly. One branch from each tree and 4 seedling stems from each host were cut and sealed with petroleum jelly to serve as controls. After 6 weeks, the outer bark was scraped away to reveal a discolored lesion marking the extent of fungus growth along the stem.

Zoospore attraction to rootlets. Zoospore suspensions were prepared as described for root inoculations. Five 1-cmlong, actively growing root tips were cut from a Port Orford cedar seedling and a Pacific yew seedling. Two root tips were cut from a Douglas fir (Pseudotsuga menziesii) seedling as a control. One root tip was floated on $10 \mathrm{ml}$ of zoospore inoculum in a 60 - by $15-\mathrm{mm}$ petri plate. Plates were assembled $5 \mathrm{~min}$ apart to allow time for root examination, and the process was repeated a total of four times. Zoospore concentrations for experimental replications 1 to 4 ranged between 1.6 and $1.8 \times 10^{5}$ spores $/ \mathrm{ml}$. The number of encysted zoospores on the root sections was estimated microscopically after $15 \mathrm{~min}, 1 \mathrm{~h}$, and $4 \mathrm{~h}$. Zoospores tended to encyst in layers around the root circumference, which made determining exact numbers impossible, so a rating system of spores per root section was devised, where $0=0$ to 10 spores, $1=11$ to 100 spores, $2=101$ to 500 spores, $3=501$ to 1000 spores, and $4=$ more than 1,000 spores. A rating was given to each of 4 sections of each root: the rounded root cap, the zone of elongation (the next $2 \mathrm{~mm}$ ), the

Table 1. Mortality of Pacific yew seedlings and rooted cuttings from two sources (Group 1 and Group 2), and Port Orford cedar seedlings 15 weeks after inoculation with Phytophthora lateralis by root dip in zoospore suspension or soil infestation with a chlamydospore suspension followed by flooding

\begin{tabular}{|c|c|c|c|c|}
\hline \multirow[b]{3}{*}{ Plant material } & \multicolumn{4}{|c|}{ Inoculum } \\
\hline & \multicolumn{2}{|c|}{ Zoospores } & \multicolumn{2}{|c|}{ Chlamydospores } \\
\hline & Number & $\%$ Mortality & Number & \% Mortality \\
\hline \multicolumn{5}{|l|}{ Inoculated } \\
\hline Yew seedlings & 25 & 16 & 25 & 0 \\
\hline Yew cuttings & 20 & 0 & 20 & 0 \\
\hline Cedar seedlings & 18 & 100 & 18 & 44 \\
\hline \multicolumn{5}{|l|}{ Control } \\
\hline Yew seedlings & 6 & 0 & 6 & 0 \\
\hline Yew cuttings & 6 & 0 & 6 & 0 \\
\hline Cedar seedlings & 4 & 0 & 4 & 0 \\
\hline
\end{tabular}

region of maturation (the next 6 or $7 \mathrm{~mm}$ ), and the surface of the cut end.

Stream survey. In the summer of 1993 , $0.8-\mathrm{km}(0.5-\mathrm{mi}$.) sections of 3 streams in southwest Oregon and northwest California were surveyed for live and dead Port Orford cedar and Pacific yew. The streams surveyed included the upper reaches of the Middle Fork of the Smith River and an unnamed tributary of Coon Creek which flows into the South Fork of the Smith River, both located on the Gasquet Ranger District of Six Rivers National Forest, northern California; and Elder Creek, located on the Illinois Valley Ranger District, Siskiyou National Forest, in southwest Oregon. The drainages were chosen based on a known history of Port Orford cedar root rot, and the current presence of mature Port Orford cedar and Pacific yew. Stand histories were determined from interviews with District Silviculturalists and by field observation.

The Middle Fork of the Smith River (T17N R5E Sec. 6) was the largest stream sampled, with a width up to $12 \mathrm{~m}$. The segment flows through a floodplain where cedar mortality has occurred up to $30 \mathrm{~m}$ from the river's edge. The terrain is nearly level, with a stream gradient ranging from 0 to $20 \%$, until near the end of the segment, where the river enters a steep canyon. The overstory is dominated by Douglas fir and Port Orford cedar. Past management history includes upstream clearcutting and road-building dating back to the 1960s. Phytophthora lateralis was most likely introduced in 1986 after a precommercial thinning.

The segment at Coon Creek (T16N R2E Sec. 21) varies from 1.5 to $6 \mathrm{~m}$ wide, and the gradient of the drainage bottom ranges from 5 to $30 \%$. The overstory is dominated by large Port Orford cedar and Douglas fir. $P$. lateralis was known to be in the area by 1984 from unknown introduction; however, management activities in the past have included mining and wood cutting.

Elder Creek (T40S R7W Sec. 19 and 20) is 1.5 to $4.5 \mathrm{~m}$ wide. The stream occurs in a small canyon, but the terrain along the stream bottom is nearly level, with a gradient of 5 to $15 \%$. The overstory was domi-

Plant Disease / December 19971401 
nated by Port Orford cedar. The first roads were built in the area in the mid-1960s, and past management included clearcutting and selective harvesting upslope from the survey area. $P$. lateralis was known to be in the area by the mid-1970s.

Every Port Orford cedar and Pacific yew tree located within $9 \mathrm{~m}$ of either side of the seasonal high water line (determined where stream-bank vegetation begins) of each stream was recorded by size class (less than $12.4 \mathrm{~cm}$ diameter or more than 12.5 $\mathrm{cm}$ diameter) and condition. Recently killed trees were examined at the root collar for the characteristic stain in the inner bark caused by $P$. lateralis. Where a lesion was evident, direct isolation was attempted on corn meal agar with 10 ppm pimaricin. Older mortality was ascribed to $P$. lateralis if indicators of other agents (breakage, animal damage) were not present and a probable source of $P$. lateralis inoculum was evident. Inner bark from the base of 63 Pacific yew trees that had been dead for several years was tested for Phytophthora using a commercial enzyme-linked immunosorbent assay kit (ELISA; Neogen Corp., Lansing, MI).

\section{RESULTS}

Root inoculations. In each of the root inoculation tests, more Port Orford cedar trees were killed than Pacific yew (Table 1). Overall mortality of inoculated trees was $72 \%$ for Port Orford cedar and only $4 \%$ for Pacific yew seedlings and cuttings. Yew mortality occurred only among Group 1 seedlings inoculated with zoospores (4 of 10 seedlings died). All of the inoculated Port Orford cedar seedlings died in that test. No control trees died in any of the tests. Root necrosis was present on all inoculated trees, but was more extensive on Port Orford cedar seedlings. Up to 25\% of the root mass of surviving yews was necrotic after 15 weeks. $P$. lateralis was recovered by baiting from roots of all zoospore-inoculated Pacific yew and Port Orford cedar trees 15 weeks after inoculation and from $72 \%$ of chlamydospore-inoculated yew trees. Recovery was $84 \%$ from chlamydospore-inoculated Port Orford cedar. No Phytophthora was recovered from any control trees.
Stem and branch inoculations. Lesions caused by P. lateralis were shorter in wound-inoculated Pacific yew seedling stems and excised branches than in comparable Port Orford cedar material. The lesion length in Pacific yew stem and branch inoculations averaged 65.8 and $22.3 \mathrm{~mm}$, respectively, while the Port Orford cedar stem and branch lesion lengths averaged 96.4 and $82.2 \mathrm{~mm}$ (Table 2). Necrosis resulting from control inoculations did not extend more than $1 \mathrm{~mm}$ beyond the limits of the wound.

Zoospore attraction to roots. More zoospores encysted on Port Orford cedar roots than on Pacific yew roots at every time period. After $4 \mathrm{~h}$ the number of zoospores that had encysted on Port Orford cedar was significantly greater than on Pacific yew over 3 of the 4 root segments. On the cedar roots, zoospores encysted most commonly on the zone of elongation and in specific areas along the region of maturation, in layers up to 10 deep. Zoospores were constantly swarming around the roots, and those that did not encyst on the root encysted on the bottom of the dish just below where the root tip floated. On the Pacific yew roots, however, zoospores encysted in clumps on root hairs in the region of maturation, but did not otherwise aggregate more specifically in one area than in another. Zoospores did not aggregate or swarm specifically around the Douglas fir roots, and those that did encyst on the roots themselves may have done so by chance, for there was no pattern or preference of zoospore encystment anywhere on the root.

Significant differences were seen between cedar and Pacific yew on all root segments except for the region of maturation $(P \leq 0.05)$. On Port Orford cedar roots, the greatest concentration of encysted zoospores occurred at the zone of elongation, while on Pacific yew the greatest concentration of encysted zoospores occurred along the region of maturation. In both species, fewest zoospores encysted on the cut end.

Stream survey. A total of 2,586 Port Orford cedar and 837 Pacific yew trees were located along the 3 stream segments. Nearly all of the mortality observed in Port
Orford cedar and in Pacific yew along the surveyed streams was ascribed to $P$. lateralis. Diagnostic red-brown phloem lesions were evident near the root collar of all dying trees. P. lateralis was regularly isolated from recently killed trees (data not shown), but as in previous studies, the fungus was not recovered from trees dead for more than a year or two (9). Positive ELISA reactions were obtained from dead trees with intact bark that had grown in positions vulnerable to Phytophthora infection. Negative reactions resulted from trees that were judged to have died from drought or other causes (data not shown). The ELISA test does not distinguish among species of Phytophthora, but $P$. lateralis is the only species that has been confirmed from either Port Orford cedar or Pacific yew growing in forests (but, see Middleton and Baxter [12]).

Pacific yews dead or dying from $P$. lateralis were all located on stream banks downstream from concentrations of Port Orford cedar killed by the fungus. Dead Port Orford cedar were also found away from the stream bank, in locations affected by seasonal floods, or adjacent to other sources of the fungus such as game trails or runoff from upslope roads.

Port Orford cedar trees were more numerous and larger than Pacific yew trees on the surveyed stream segments, and a greater proportion of the Port Orford cedar trees were dead. In total, $46 \%$ of Port Orford cedar growing within $9 \mathrm{~m}$ of the streams were dead, compared to $10 \% \mathrm{~Pa}$ cific yew mortality. The amount of cedar mortality was greater than the amount of Pacific yew mortality within each drainage (Table 3). About equal numbers of large Port Orford cedar (diameter greater than 12 $\mathrm{cm}$ ) and smaller trees were present, but $61 \%$ of the larger trees were dead, compared to $32 \%$ of the smaller. Large Pacific yew were less frequently encountered, and there was no clear indication that they suffered disproportionate mortality compared to smaller yew trees.

\section{DISCUSSION}

Results of the root inoculations, branch and stem inoculations, zoospore attraction experiments, and stream survey all support

Table 2. Mean lesion length, including the 10-mm incision, of Pacific yew and Port Orford cedar (POC) seedling stems and mature tree branches 6 weeks after inoculation with Phytophthora lateralis

\begin{tabular}{|c|c|c|c|c|c|c|c|c|c|c|c|c|}
\hline \multirow[b]{3}{*}{ Species } & \multirow{2}{*}{\multicolumn{3}{|c|}{ Stem lesions }} & \multicolumn{9}{|c|}{ Branch lesions } \\
\hline & & & & \multicolumn{3}{|c|}{ Corvallis $^{x}$} & \multicolumn{3}{|c|}{ Siskiyou $^{\mathrm{y}}$} & \multicolumn{3}{|c|}{ All } \\
\hline & Number & Mean & (SD) & Number & Mean & (SD) & Number & Mean & (SD) & Number & Mean & (SD) \\
\hline$\overline{\text { Yew }}$ & 30 & 65.8 & (33.4) & 30 & 29.9 & (6.7) & 35 & 15.8 & $(5.0)$ & 65 & 22.3 & $(9.5)$ \\
\hline Yew-c ${ }^{\mathrm{z}}$ & 4 & 10.0 & $(2.2)$ & 6 & 9.7 & (1.9) & 7 & 9.6 & (1.0) & 13 & 9.6 & (1.4) \\
\hline POC & 15 & 96.4 & (18.8) & 5 & 86.2 & (29.3) & 10 & 80.2 & (22.9) & 15 & 82.2 & (24) \\
\hline POC-c & 4 & 10.7 & $(1.2)$ & 2 & 12.0 & $(0.7)$ & 2 & 11.0 & (1.4) & 3 & 12.0 & (2.0) \\
\hline
\end{tabular}

${ }^{\mathrm{x}}$ Corvallis branches taken from Pacific yew trees in MacDonald-Dunn Experimental Forest, and from Port Orford cedar on the Oregon State University campus.

y Siskiyou branches taken from Pacific yew and Port Orford cedar trees in Elder Creek, Siskiyou National Forest.

${ }^{\mathrm{z}}$ Control branches and stems. 
the conclusion that Pacific yew is less susceptible to $P$. lateralis than is Port Orford cedar. In each of the 4 root inoculation tests, there was less root necrosis and less mortality on Pacific yew than on Port Orford cedar.

Yew mortality was observed in only 1 test, with Group 1 seedlings. These seedlings also exhibited more root necrosis. The trees were larger and appeared to be more vigorous than Group 2 seedlings, but the Group 1 trees were survivors of a larger group that had suffered from a severe infestation of root weevils. It is possible that the inoculated Group 1 seedlings had been infested by weevils as well, although visible damage was not evident at the time of inoculation. Perhaps weevil feeding had created additional infection courts on these seedlings, allowing more rapid Phytophthora colonization.

The field survey of infested drainages further supports the conclusion that Pacific yew is a less-susceptible host of $P$. lateralis than Port Orford cedar. The proportion of dead Port Orford cedar in each drainage was significantly greater than the proportion of dead Pacific yew, and yew mortality was sporadic while Port Orford cedar mortality was almost continuous along stream banks. The overall mortality of Pacific yew, however, was much greater than previously reported. Based on the degree of deterioration of dead trees observed in this and other surveys, it appears that Pacific yew mortality along an infested stream begins about 5 years after Port Orford cedar mortality. Dead yews are concentrated downstream of areas of dead cedar, usually growing on the stream bank. Yews growing in well-drained soil away from the stream are less likely to be killed, even if dead Port Orford cedar trees are in the vicinity.

Branch and stem inoculation results supported root inoculation results, similar to studies by Hansen and Hamm (10) with Port Orford cedar and $P$. lateralis, by Browne and Mircetich (3) with apple and P. cactorum, P. cambivora, and P. crypto-

Table 3. Live and dead (Phytophthora lateralis mortality only) Port Orford cedar and Pacific yew within $9 \mathrm{~m}$ of stream centers along $0.8-\mathrm{km}$ segments of three streams in southwest Oregon and northwest California

\begin{tabular}{|c|c|c|c|c|}
\hline \multirow[b]{2}{*}{ Size Class } & \multicolumn{2}{|c|}{ Port-Orford-cedar } & \multicolumn{2}{|c|}{ Pacific yew } \\
\hline & Total & Dead $(\%)$ & Total & Dead $(\%)$ \\
\hline \multicolumn{5}{|c|}{ Middle Fork of the Smith River } \\
\hline$\leq 12 \mathrm{~cm} \mathrm{DBH}^{\mathrm{z}}$ & 391 & 48 & 324 & 10 \\
\hline$>12 \mathrm{~cm} \mathrm{DBH}$ & 504 & 39 & 74 & 18 \\
\hline Total & 895 & 28 & 398 & 11 \\
\hline \multicolumn{5}{|l|}{ Coon Creek } \\
\hline$\leq 12 \mathrm{~cm} \mathrm{DBH}$ & 485 & 48 & 47 & 32 \\
\hline$>12 \mathrm{~cm} \mathrm{DBH}$ & 344 & 89 & 4 & 25 \\
\hline Total & 829 & 65 & 51 & 31 \\
\hline \multicolumn{5}{|l|}{ Elder Creek } \\
\hline$\leq 12 \mathrm{~cm} \mathrm{DBH}$ & 421 & 32 & 342 & 7 \\
\hline$>12 \mathrm{~cm} \mathrm{DBH}$ & 441 & 62 & 46 & 4 \\
\hline Total & 862 & 47 & 388 & 6 \\
\hline
\end{tabular}

${ }^{\mathrm{z}} \mathrm{DBH}=$ diameter at breast height $(1.4 \mathrm{~m})$. gea, and by Afek and Sztejnberg (1) with citrus stems and $P$. citrophthora. Lesion growth of $P$. lateralis in Port Orford cedar was much faster than in Pacific yew in both the tree branches and in the intact seedling stems.

Observations of zoospore aggregation on roots suggest that far fewer zoospores encyst on Pacific yew roots than on cedar roots, given the same approximate inoculum concentration and time of exposure. The primary location of zoospore encystment on the Port Orford cedar roots was similar to that observed by Zentmeyer (18) for $P$. cinnamomi zoospores on small feeder roots of avocado. More zoospores encysted on the zone of elongation than on the root apex or the region of maturation.

Zoospores on Pacific yew rootlets most commonly encysted on root hairs along the region of maturation. The region of maturation represented the largest surface area of the four rootlet segments.

Stem inoculation and zoospore attraction experiments suggest reasons for the reduced susceptibility of Pacific yew compared to Port Orford cedar. Fewer zoospores encyst on yew roots than on Port Orford cedar, and established infections extend more slowly in the phloem tissue. Together, these observations suggest that inoculum potential must be considerably higher for successful infection of yew. Once established, the slower lesion-elongation rate increases the period of survival of infected trees, but also increases the long-term chances of survival. Seasonal drought and associated dieback of fine roots, for example, have a greater chance of halting a slow moving infection than one that advances rapidly.

In all tests, Pacific yew was much less susceptible than Port Orford cedar to $P$. lateralis. However, the fact that $P$. lateralis was reisolated from a majority of the inoculated Pacific yew seedlings and cuttings should not be overlooked. Pacific yew could maintain populations of $P$. lateralis in infested drainages while itself surviving exposure to the pathogen. Such conditions would hinder the future reintroduction of Port Orford cedar. In areas where the two hosts occur together, an increased risk of mortality of Port Orford cedar may occur over a longer period of time due to the presence of Pacific yew. When Port Orford cedar is removed from an area to reduce chances for inoculum increase and to hasten the demise of the fungus on the site, the removal of living Pacific yew should be considered as well.

It has been suggested (19) that $P$. lateralis might be native to northwestern North America, north of the present range of Port Orford cedar. Demonstration that Pacific yew is a host to the fungus, and rather tolerant of infection, adds some credence to this idea. The slow-growing Pacific yew is associated with a variety of conifer and hardwood tree species in other areas. It grows on several different soil types and altitudinal zones, from the southern tip of southeast Alaska to Calaveras County, California, and is usually found scattered on upland sites or sporadically in riparian areas (2). Pacific yew is most abundant, however, in southern Oregon, where it is often mixed with Port Orford cedar, and in the northern Rocky Mountains (4,7).

This work suggests that $P$. lateralis will have limited impact on the native population of Pacific yew over most of its range. Unusual mortality of Pacific yew has not been observed except where it is growing with Port Orford cedar. In the native range of Port Orford cedar, however, P. lateralis does have the potential to alter the population of Pacific yew along streams where the species grow together.

\section{ACKNOWLEDGMENTS}

We thank Weyerhaeuser Company and the J. Herbert Stone Nursery, USDA Forest Service for the donation of yew seedlings and rooted cuttings.

\section{LITERATURE CITED}

1. Afek, U., and Sztejnberg, A. 1990. A rapid method for evaluating citrus seedlings for resistance to foot rot caused by Phytophthora citrophthora. Plant Dis. 74:66-68.

2. Bolsinger, C., and Jaramillo, A. 1990. Taxus brevifolia Nutt. Page 573 in: Silvics of North America, vol. 1: Conifers. U. S. Dep. Agric. For. Serv. Handb. No. 654.

3. Brown, G. T., and Mircetich, S. M. 1993. Relative resistance of thirteen apple rootstocks to three species of Phytophthora. Phytopathology 83:744-749.

4. Daubenmire, R. F., and Daubenmire, J. B. 1968. Forest vegetation of eastern Washington and northern Idaho. Agric. Exp. Stn. Tech. Bull. No. 60. Washington State University, Pullman.

5. DeNitto, G., and Kliejunas, J. T. 1991. First Report of Phytophthora lateralis on Pacific yew. (Abstr.) Plant Dis. 75:968.

6. Englander, L., and Roth, L. F. 1980. Interaction of light and sterol on sporangium and chlamydospore production by Phytophthora lateralis. Phytopathology 70:650-655.

7. Franklin, D. J., and Dyrness, C. T. 1972. Natural vegetation of Oregon and Washington. U.S. Forest Service Gen. Tech. Rep. PNW-8. Pacific Northwest Experiment Station, Portland, OR.

8. Hamm, P. B., and Hansen, E. M. 1984. Im- 
proved method for isolating Phytophthora lateralis from soil. Plant Dis. 68:517-519.

9. Hansen, E. M., and Hamm, P. B. 1996. Survival of Phytophthora lateralis in infected roots of Port Orford cedar. Plant Dis. 80:1075-1078

10. Hansen, E. M., Hamm, P. B., and Roth, L. F. 1989. Testing Port Orford cedar for resistance to Phytophthora. Plant Dis. 73:791-794.

11. Hartzell, H., Jr. 1991. The Yew Tree: A Thousand Whispers. Hulogisi Printing, Eugene, $\mathrm{OR}$.

12. Middleton, J. T., and Baxter, D. V. 1955. The occurrence of Phytophthora and Pythium species on roots of native plants in northern California and southern Oregon. (Abstr.) Phyto- pathology 45: 694

13. Nicolaou, K. C., Yang, Z., Liu, J. J., Ueno, H., Nantermet, P. G., Guy, R. K., Claiborne, C. F., Renaud, J., Couladouros, E. A., Paulvannan, K., and Sorensen, E. J. 1994. Total synthesis of taxol. Nature 367:630-634.

14. Roth, L. F., Trione, E. J., and Ruhmann, W. H. 1957. Phytophthora induced root rot on native Port Orford cedar. J. For. 55:294-298.

15. Trione, E. J. 1959. The pathology of Phytophthora lateralis on native Chamaecyparis lawsoniana. Phytopathology 49:306-310.

16. Tucker, C. M., and Milbrath, J. A. 1942. Root rot of Chamaecyparis caused by a species of Phytophthora. Mycologia 34:94-101.

17. Wani, M. C., Taylor, H. L., Wall, M. E., Cog- gon, P., and McPhail, A. T. 1971. Plant antitumor agents VI. The isolation and structure of taxol, a novel antileukemic and antitumor agent from Taxus brevifolia. J. Am. Chem. Soc. 93:2325-2327.

18. Zentmeyer, G. A. 1980. Phytophthora cinnamomi and the diseases it causes. Monograph No. 10. The American Phytopathological Society, St. Paul, MN

19. Zobel. D. B., Roth, L. F., and Hawk, G. M 1985. Ecology, Pathology, and Management of Port Orford cedar (Chamaecyparis lawsoniana). General Technical Report, PNW184, Portland, OR, USDA Forest Service, Pacific Northwest Regional Experiment Station. 